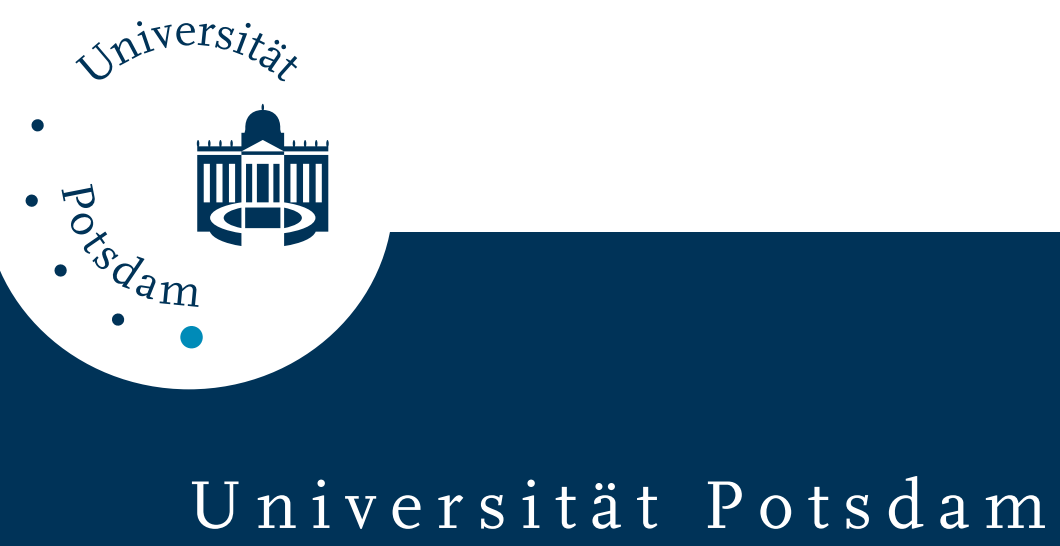

Thilo Heinken, Eckart Winkler

Non-random dispersal by ants : long-term field data versus model predictions of population spread of a forest herb

first published in:

Perspectives in plant ecology, evolution and systematics. - 11 (2009), 1,

S. 1 - 15, DOI 10.1016/j.ppees.2008.11.001

Postprint published at the Institutional Repository of the Potsdam University:

In: Postprints der Universität Potsdam

Mathematisch-Naturwissenschaftliche Reihe ; 151

http://opus.kobv.de/ubp/volltexte/2010/4648/

http://nbn-resolving.de/urn:nbn:de:kobv:517-opus-46482

Postprints der Universität Potsdam

Mathematisch-Naturwissenschaftliche Reihe ; 151 



\title{
Non-random dispersal by ants: long-term field data versus model predictions of population spread of a forest herb
}

\author{
Thilo Heinken ${ }^{\mathrm{a},{ }^{,},}$Eckart Winkler ${ }^{\mathrm{b}}$ \\ ${ }^{a}$ Department of Community Ecology/Botany, University of Potsdam, Maulbeerallee 1, D- \\ 14469 Potsdam, Germany \\ ${ }^{b}$ Department of Ecological Modelling, UFZ Helmholtz Centre for Environmental Research, \\ P.O. Box 500 135, D-04301 Leipzig, Germany \\ * Corresponding author. Tel.: +49 331977 4854; fax: +49 3319774865 \\ E-mail address: heinken@uni-potsdam.de (T. Heinken)
}

\begin{abstract}
Myrmecochory, i.e. dispersal of seeds by ants towards and around their nests, plays an important role in temperate forests. Yet hardly any study has examined plant population spread over several years and the underlying joint contribution of a hierarchy of dispersal modes and plant demography. We used a seed-sowing approach with three replicates to examine colonization patterns of Melampyrum pratense, an annual myrmecochorous herb, in a mixed Scots pine forest in northeastern Germany. Using a spatially explicit individualbased (SEIB) model population patterns over 4 years were explained by short-distance transport of seeds by small ant species with high nest densities, resulting in random spread. However, plant distributions in the field after another 4 years were clearly deviating from model predictions. Mean annual spread rate increased from $0.9 \mathrm{~m}$ to $5.1 \mathrm{~m}$ per year, with a clear inhomogeneous component. Obviously, after a lag-phase of several years, non-random seed dispersal by large red wood ants (Formica rufa) was determining the species' spread, thus resulting in stratified dispersal due to interactions with different-sized ant species. Hypotheses on stratified dispersal, on dispersal lag, and on non-random dispersal were verified using an extended SEIB model, by comparison of model outputs with field patterns (individual numbers, population areas, and maximum distances). Dispersal towards red wood ant nests together with seed loss during transport and redistribution around nests were essential features of the model extension. The observed lag-phase in the initiation of non-random, medium-distance transport was probably due to a change of ant behaviour towards a new food source of increasing importance, being a meaningful example for a lag-phase in local plant species invasion. The results demonstrate that field studies should check model predictions wherever possible. Future research will show whether or not the $M$. pratense-ant system is representative for migration patterns of similar animal dispersal systems after having crossed range edges by long-distance dispersal events.
\end{abstract}

Keywords: Melampyrum pratense, Population dynamics, Seed dispersal, Non-random dispersal, Plant-animal interaction, Individual-based model

\section{Introduction}

As site conditions for plants are nowadays rapidly altered by changing land use, pollution, and climate change, survival of species will depend, to a considerable extent, on their dispersal and colonization abilities (Midgley et al., 2006; Thuiller et al., 2008). Dispersal potential also mediates the spread of invasive plant species (Neubert and Caswell, 2000; Buckley et al., 2006). However, any predictions on migration in changing landscapes are limited by inadequate data for key processes at different time and spatial scales (Neilson et al., 2005) and by a limited ability to combine this knowledge. Only recently, attempts have been made to consider as many spatial and temporal details that are necessary for reliable statements (Volin et al., 2004; Midgley et al., 2006). Increasingly sophisticated dispersal models com- 
bined with spatially explicit simulations of population dynamics are a promising tool for enlarging our understanding in this regard (Buckley et al., 2006).

Forest herbs of northern temperate forests in Europe and NE America offer convenient examples of spatially limited species, their local distribution being determined by seed availability and thus dispersal (Ehrlén and Eriksson, 2000; Flinn and Vellend, 2005; van der Veken et al., 2007). Ants are the most common seed dispersal agent for herbs in these forests (Whigham, 2004), and myrmecochory (i.e. dispersal of seeds by ants) is found in more than 3000 plant species from more than 80 plant families worldwide (Beattie and Hughes, 2002). Ants move seeds on a strictly local scale (Gomez \& Espadaler 1998), and dispersal patterns of several myrmecochorous seed species are well documented (e.g. Higashi et al., 1989; Gibson, 1993).

As colonization and migration processes are determined also by population growth (Neubert and Caswell, 2000; Thuiller et al., 2008), knowledge of both dispersal and population dynamics is necessary to understand species' spread patterns. Contrary to dispersal distances, little is known about ant-mediated spread patterns and migration rates of herbaceous forest plants over long time periods. Few studies have been done in young stands of known age adjacent to ancient forests (Matlack, 1994; Brunet and von Oheimb, 1998). Because here spread patterns are influenced by environmental differences between stand types (Flinn and Vellend, 2005), such studies need to be supplemented with direct observations of plant population development from known release points in homogenous forest stands. However, studies tracking species' spread following experimental introduction are scarce because they have to be monitored for several years (but see Primack and Miao, 1992; Petersen and Philipp, 2001; van der Veken et al., 2007).

Heinken (2004) used a seed-sowing approach in 1997 to examine colonization patterns of Melampyrum pratense, an annual myrmecochorous forest herb in a previously uncolonized recent forest in Germany. Until 2001 all populations spread almost isotropically around the area of origin. Population sizes, starting with approximately 30 individuals, increased exponentially up to 500-1300 individuals. Population areas increased steadily from $1 \mathrm{~m}^{2}$ up to $35-40 \mathrm{~m}^{2}$, the farthest individuals being less than $10 \mathrm{~m}$ off the sowing plot. For the explanation of these field patterns we designed a simulation model that integrated population dynamics with mechanisms of seed dispersal (Winkler and Heinken, 2007). Basic parameters for this stochastic spatially explicit individual-based (SEIB) model were estimated on the basis of the empirical data both from the experiment and from literature. During the first 4 years after introduction population spread was well described by a primary deposition (barochory) and a secondary transport of seeds by small ant species with high nest densities and random activity over short distances, resulting in patterns of a random isotropic spread. We also demonstrated that the population had a high benefit from this interaction with ants. The model allowed projecting further population spread over several years giving testable hypotheses on future population development.

We revisited the study sites in 2005 and found population distribution patterns that were deviating strongly from the model predictions only 4 years earlier. These new, inhomogeneous patterns gave rise to the hypotheses that now, after a lag-phase of several years, nonrandom seed dispersal by large red wood ants towards and around their conspicuous nest mounds was determining the species' spread, leading to stratified dispersal due to interactions with differently sized ant species. Our hypotheses on (a) stratified dispersal, (b) dispersal lag and (c) non-random dispersal were to be verified, after implementation into an extended version of the SEIB model, by systematic comparison of model outputs with characteristics of the field patterns.

Beyond the question of forest-herb spread we assumed that the detailed record of a lagphase in population development will also shed some light on the initial phase of species invasion in general. In the majority of case studies plant invasions are examined only retrospectively and they rarely describe the whole process of spread from its beginning (Pyšek and Hulme, 2005). We intended to contribute to the knowledge of invasion initiation by a study of the small-scale spread pattern of a native species spreading into a new habitat.

In the present study we first give an overview over the extended version of the stochastic SEIB model for $M$. pratense that includes non-random dispersal by red wood ants and a lag- 
phase in the emergence of stratified dispersal. We then present and evaluate field patterns from the development and spatial spread of populations over 4 and 8 years after artificial introduction of seeds at three study sites. These patterns will make it possible to determine model parameters and to elucidate the interactions of dispersal mechanisms in generating observed population increase and spread. We finally discuss our empirical and theoretical findings in light of plant-animal mutualism, of causes for a delay in the initial phase of plant invasions, and of our ability to obtain reliable model predictions.

\section{Material and methods The species}

Our study species, Melampyrum pratense L. (formerly Scrophulariaceae, now Orobanchaceae; see Olmstead et al. 2001), is common in mixed oak and pine forests on acidic soils in northern Germany. It is an annual hemiparasite on woody plants such as Betula spp., Quercus spp. and Pinus sylvestris L. as hosts (e.g. Masselink, 1980). While cotyledons and green shoots emerge in spring, $M$. pratense flowers during the whole summer and fruits until autumn. The large ovoid seeds which are found in capsules have a mean dry weight of 3.95 mg (Heinken, 2004), and their number per plant is low (Winkler and Heinken, 2007: 2-227, mean 59). Seeds fall within a very short distance from the parental plant, i.e. they simply drop from the capsules (primary dispersal, 'barochory'). Seeds have an elaiosome and are readily taken and dispersed by ants (e.g. Formica rufa L., F. fusca L. and Myrmica ruginodis Nyl.) after being released (secondary dispersal, 'myrmecochory'). Thompson et al. (1997) rate $M$. pratense as forming a transient seed bank.

\section{Field study}

The field experiment was carried out in the "Glauer Berge" forest area in north-eastern Germany (lat $52^{\circ} 15^{\prime}$, long $13^{\circ} 08^{\prime}-13^{\circ} 11^{\prime}$ ), an isolated mixed Scots pine forest stand with dry acidic sands within an agricultural landscape. Natural populations of $M$. pratense are missing in this area due to dispersal limitation because the forest has only been established since the $19^{\text {th }}$ century. Heinken (2004) chose three largely homogenous sites which appeared to be suitable for populations of $M$. pratense. Nest densities of small seed-dispersing ant species (Formica fusca, Myrmica spp.) amount to $>10$ nests per $100 \mathrm{~m}^{2}$ (Winkler and Heinken, 2007), while around 2.5-3.0 nest mounds per ha of the large colonies of red wood ants (Formica rufa L.) were recorded in 2005.

To each site 300 seeds of $M$. pratense with regional provenance were introduced in a $1 * 1$ $\mathrm{m}^{2}$ plot in autumn 1997. Development of population sizes and colonization patterns were then investigated by mapping the position of all adult plant individuals in August from 1998 through 2001 within $10^{*} 10 \mathrm{~cm}$ grids covering the actual population areas. Wider areas $(d=$ $50 \mathrm{~m}$ ) were checked for the conspicuous $M$. pratense individuals without any success. Population maps were shown by Heinken (2004) and Winkler and Heinken (2007).

In September 2005 (8 years after introduction) we surveyed the three M. pratense populations again. Due to the ongoing massive population growth and spread we now estimated the number of individuals within a coarser grid of $25^{\star} 25 \mathrm{~cm}^{2}$. We classified the grid cells according to their number of individuals: class 1 with $n=1$, class 2 with $n=2$, class 3 with $n=$ $3-5$, class 4 with $n=6-10$, and class 5 with $n>10$ individuals. To estimate the total individual number, we used mean individual numbers of grid cells within the respective size classes for each population from 1998-2001. An area of $d=200 \mathrm{~m}$ around each sown plot was checked for M. pratense individuals. As distribution patterns of plants were now obviously related to nest mounds of the red wood ant, the positions of ant hills were mapped around each sown plot $(d=200 \mathrm{~m})$. We also mapped small regions showing only sparse understorey vegetation (see site-specific establishment rules).

\section{Data analysis}

For visualisation we designed distribution maps of $M$. pratense for 2001 and 2005 on a $100 * 100 \mathrm{~cm}^{2}$ grid scale (see Fig. 2-4). To obtain the distribution data of both censuses we defined 16 sectors radiating from the centre of the sown plot and corresponding with the 
compass directions (see Heinken, 2004). Expansion rates were determined for each period of spread (1998-2001 vs. 2001-2005), population (M1, M2, M3) and sector by calculating the radial distances between the outermost $M$. pratense individuals in 1998, 2001 and 2005. We used repeated measures ANOVA to test the effects of populations on the spread rates of the two investigated phases including population as between subject factor. Contrasts between populations were analysed with Tukey post hoc test. To test for differences between the two phases (within subject factor) and for the effect of the interaction between phase and population, we used repeated-measures ANOVA (SPSS, 15.0). Contrasts within the populations were analysed with paired t-test. Variables met the assumption of normal distribution (onesample Kolmogorov-Smirnov test).

Contrasts between populations were analysed with Tukey post hoc test. To test for differences between the two phases and for the effect of the interaction between phase and population we used repeated-measures ANOVA (SPSS, 12.0). Contrasts within the populations were analysed with paired t-test.

\section{Simulation model \\ General structure}

We designed an individual-based model of plant population dynamics of $M$. pratense to match the full set of empirical results starting from the model of Winkler and Heinken (2007). Parameters that were taken from our previous model are summarized in Table 1 (for details see Winkler and Heinken, 2007), novel model parameters are listed in Table 2.

Table 1. Basic model parameters, their standard values, and model output. Sources for parameter values are: (a) experiments (Heinken 2004), (b) field mapping (Winkler and Heinken, 2007), (c) fitting of field patterns 2001 (Winkler and Heinken, 2007), (d) Masselink (1980), (e) Gibson (1993), and (f) humidity indices (Winkler and Heinken, 2007). Parameters for dispersal by red wood ants are given in Table 2.

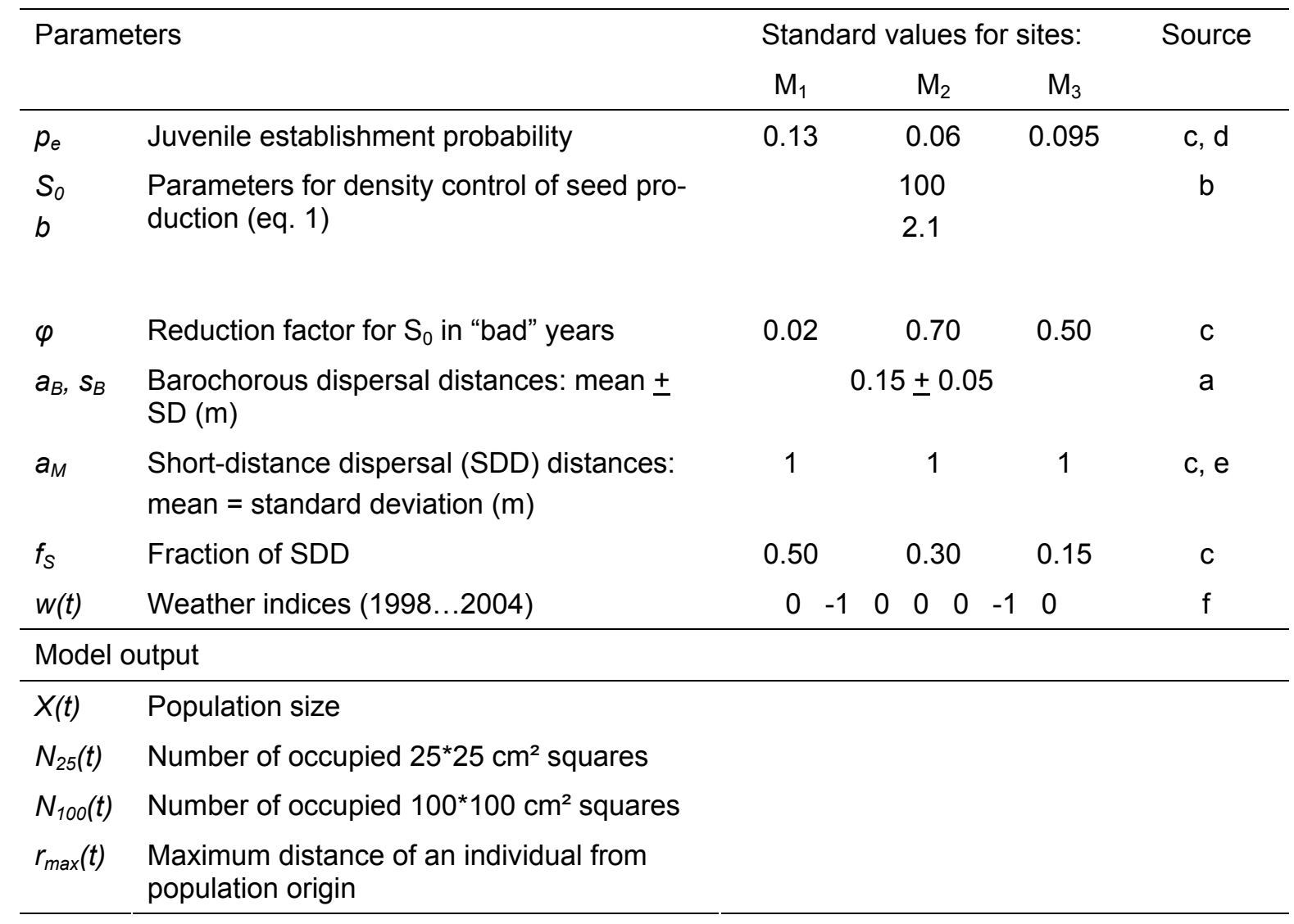


Table 2. Model parameters of dispersal by red wood ants: position of nest mounds to which seed transport obviously occurred (see Figs. 2-4), and parameters of seed dispersal (MDD) to these ant nests. For parameters $r_{i}, D$, and $p_{d}$ see dispersal rules. *: nest distance changed in $t=7$ years (see "site-specific model rules" for this assumption). Parameter sources: (a) field mapping 2005 (this study), (b) fitting of field pattern 2005 (this study), (c) Gorb and Gorb (2003).

\begin{tabular}{|c|c|c|c|c|c|c|}
\hline \multicolumn{3}{|c|}{ Parameters } & \multicolumn{3}{|c|}{ Values for sites: } & \multirow[t]{2}{*}{ Source } \\
\hline & & Nest & M1 & M2 & M3 & \\
\hline B & $\begin{array}{l}\text { Fraction of medium-distance dispersal } \\
\text { (MDD) (eq. 3) }\end{array}$ & & 0.1 & 0.55 & 0.5 & $\mathrm{~b}$ \\
\hline \multirow[t]{3}{*}{$R$} & Distance population origin - nest $(\mathrm{m})$ & 1 & 27 & 25 & $30 / 36^{*}$ & a \\
\hline & & 2 & - & 34 & 30 & \\
\hline & & 3 & - & 41 & 77 & \\
\hline$A$ & Nest area $\left(m^{2}\right)$ & & & 1 & & a \\
\hline$R$ & Distance seed production - nest & & Dep & $\begin{array}{l}\text { ing on plar } \\
\text { (see eq. } 2\end{array}$ & position & \\
\hline$D$ & Width of transport route $(\mathrm{m})$ & & & 4 & & c \\
\hline \multirow[t]{3}{*}{$p_{d}$} & Dropping rate per metre & 1 & .001 & .000025 & .0000075 & $b$ \\
\hline & & 2 & - & .000010 & .00005 & \\
\hline & & 3 & - & .000015 & .000075 & \\
\hline \multirow[t]{3}{*}{$f_{R}$} & Fraction of redistribution around nest & 1 & .0025 & .025 & .4 & $b$ \\
\hline & & 2 & - & .01 & .05 & \\
\hline & & 3 & - & .0007 & 0 & \\
\hline \multirow[t]{3}{*}{$a_{R}$} & Average redistribution distance $(\mathrm{m})$ & 1 & 3 & 5 & 3.5 & $\mathrm{~b}$ \\
\hline & & 2 & - & 4 & 3.5 & \\
\hline & & 3 & - & 4 & - & \\
\hline
\end{tabular}

The model followed the life history of the species on a grid-cell base linked with ant-mediated seed dispersal between grid cells as a stratified process. "Space" was presented by $2400^{*} 1600$ cells of $5^{*} 5 \mathrm{~cm}\left(120^{*} 80 \mathrm{~m}\right)$. Each cell could host more than one individual. Dynamics were modelled in time steps of 1 year including a sequence of flowering plus seed production, dispersal and seed deposition in a transient seed bank, mortality, seedling emergence, and establishment of new adults. All individual demographic events included demographic stochasticity (random decisions, or Poisson-distributed number of seeds).

All adult individuals produced seeds at the beginning of each model cycle. Seed set $s$ per individual plant was density-dependent. The number of neighbours $\mathrm{k}$ in a square of $25^{\star} 25 \mathrm{~cm}$ around the target individual determined the parameter $S$ of a Poisson distribution of seed set $s$ by assuming a monotonous hyperbolic decrease of seed productivity with increasing neighbourhood density (see Winkler and Heinken, 2007):

$$
S=S_{0}(b+1) /(b+1+k) \text {. }
$$

Climate was assumed to affect seed production. We divided "weather" into two classes: normal years (class index $w=0$ ) and very dry years (class index $w=-1$ ); the sequence of class indices $w(t)$ derived from meteorological data is given in Table 1. If $w(t)=-1$, seedproduction $S$ was reduced by multiplication with a factor $\varphi<1$.

Seeds were dispersed sequentially assuming different mechanisms (stratified dispersal; see dispersal rules) and then deposited in the local, transient seed bank of the deposition cell. In the following year seeds germinated and gave rise to new adults with establishment probability $p_{e}$. 


\section{Dispersal rules}

The modelling of dispersal extended the set of rules given by Winkler and Heinken (2007) (Fig. 1). All seeds were deposited barochorously (mechanism 1). Individual distances were drawn from a truncated normal distribution, and dispersal directions were drawn at random.

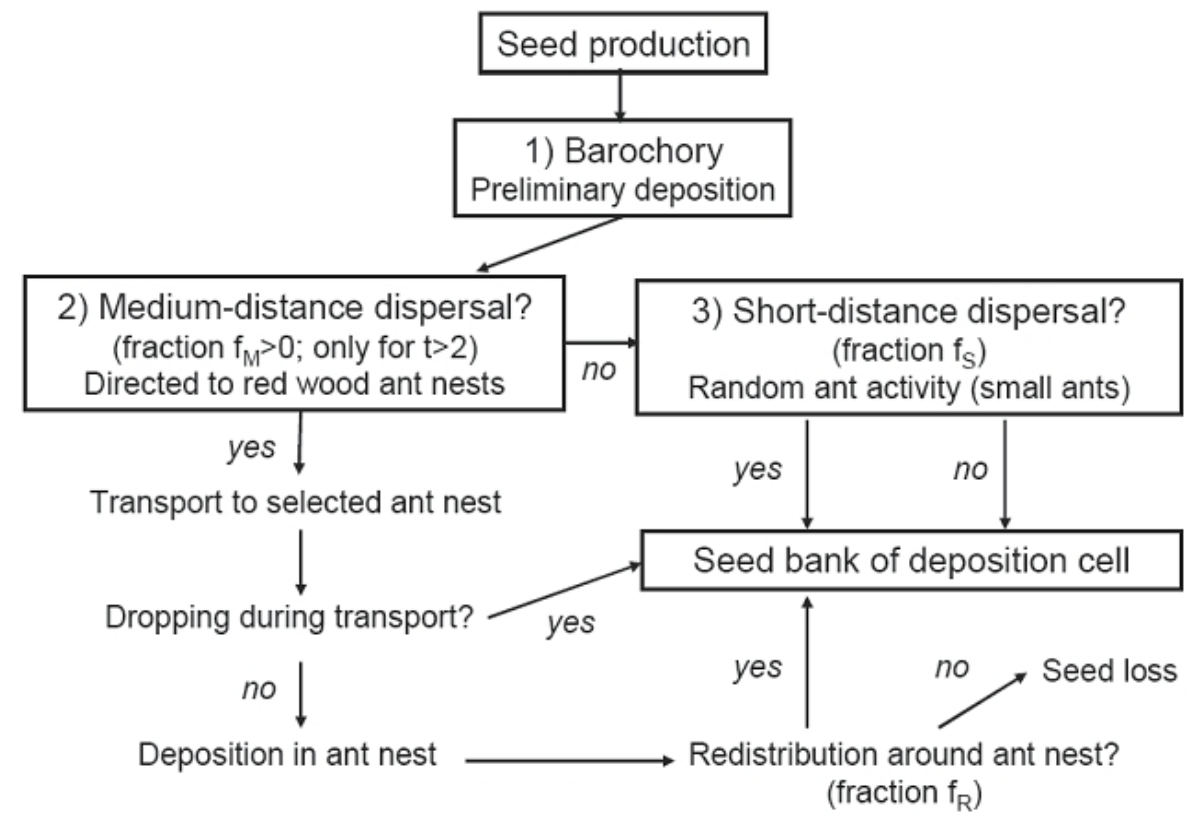

Fig. 1. Ant-mediated seed dispersal in the model: sequence of dispersal mechanisms for individual seeds within a time step $t \ldots t+1$.

Then, seeds could be transported farther by myrmecochory in two different ways: The first model decision concerned the occurrence of non-random, "medium-distance" dispersal by Formica rufa (MDD, mechanism 2; fraction $\mathrm{f}_{\mathrm{M}}$ ) over distances up to $50 \mathrm{~m}$. MDD was initiated not prior to a few years after the start of population development (see scenarios). The seeds of the fraction $f_{M}$ obeyed a sequence of deposition and loss rules mimicking transport to one of the $n$ ant nests positioned in the simulation area. The probability $p_{i}$ of a seed of fraction $\mathrm{f}_{\mathrm{M}}$ to be transported towards nest $\mathrm{i}$ was given by

$$
p_{i}=\frac{A_{i} / r_{i}}{\sum_{i} A_{i} / r_{i}}
$$

Here $A_{i}$ gives the area of nest $i$, and $r_{i}$ is the distance between the starting position of the seed (after barochory near the mother plant) and nest position. A fraction $p_{d} \cdot r_{i}$ of the seeds transported to nest i were lost by random dropping with uniform probability within the rectangle $r_{i} \cdot D$ between starting position and nest $i$ (see Table 2). This random dropping described a net result of sequences of dropping of transported seeds, of secondary transport by other ants and re-dropping (Gorb and Gorb, 2003). A fraction $f_{R}$ of the seeds arriving at ant nest $i$ was redistributed around the nest (exponentially decreasing distribution distances with parameter $\left.a_{R}\right)$. The seeds remaining - deeply buried - in the nest mound $\left(1-f_{R}\right)$ were lost as they did not germinate there (see below).

Seeds not subject to MDD had the possibility for "short-distance" dispersal by smaller ant species with small territories like F. fusca and Myrmica ruginodis (SDD, mechanism 3; fraction $f_{S}$ ) to positions up to some metres away from the point of barochorous deposition. Here, distances followed an exponential distribution with parameter $\mathrm{a}_{M}$ (following Gibson, 1993), and dispersal directions were determined at random.

Positions of red wood ant nests were taken from the field mapping (Table 2). For site M3 we introduced an ad hoc-rule for shift of ant nest 1 by a distance of $6 \mathrm{~m}$ between 2004 and 2005. 


\section{Site-specific establishment rules}

Some small habitat regions were less or non-suited for establishment of $M$. pratense and thus affected population growth. Only unsuitable habitat areas were mapped and considered, the properties of which were known independently of the species' spread. These were (1) areas of active ant nests (their surface being devoid of vegetation and continuously restructured; Laakso and Setälä 1998), (2) regions with sparse vegetation under young oak trees indicating low light intensity (site M1), and (3) a younger pine plantation which also almost lacked a herb layer (in the $\mathrm{N}$ of site $\mathrm{M} 3$ ). M. pratense is unable to grow in sites where less than $4 \%$ of PAR reach the herb layer (Heinken, 1995), which was true for the specific areas of (2) and (3) (measurements with LI-COR 190SB). The model summarized over these details which mainly concerned site M1: seedling establishment probability $p_{e}$ in the cells in question was reduced by $75 \%$ (reduced suitability) or set to zero (unsuitable habitat) over the whole simulation period.

\section{Model initialization, model output and parameter determination}

We initialized simulations by randomly distributing 300 seeds over the central area of $1 * 1$ $\mathrm{m}^{2}$ (Winkler and Heinken, 2007). We designed the model output to match characteristics observed in the field. Time-dependent population sizes $X(t)$ were given by the number of adults. To express the spatial distribution and the clumping of the individuals, the model calculated the number of all $25^{\star} 25 \mathrm{~cm}^{2}$ and of $100^{*} 100 \mathrm{~cm}^{2}$ squares $\left(n_{25}\right.$ and $\left.n_{100}\right)$ containing flowering individuals, and the maximum distance $r_{\max }$ of an individual from the population origin. Species distributions from simulations were visualized in the same way as the field data.

We took parameters describing population dynamics, barochory, and SDD (Table 1) mainly from Winkler and Heinken (2007), where they were estimated along data from 19982001 by using a least-squares procedure for stochastic models. The parameters for model extension by MDD (Table 2) were estimated in most cases by visual comparison of modelcreated maps with the 2005 distribution data: A stochastic least-squares fitting was not sensitive enough because of the large stochasticity both in the data and in the model output. This impact of stochasticity especially concerned the spread of individuals in the regions between core population and ant nests.

\section{Scenarios}

The "projection scenario" (1) used only the model rules and parameters evaluated from the first 4 years until 2001 as described by Winkler and Heinken (2007). This scenario considered already a stratified dispersal process (hypothesis 1 ), but did not include MDD $\left(f_{M}=\right.$ $0)$.

The "core-development scenario" (2) additionally considered an apparent loss of seed by MDD after a lag-phase (hypothesis 2). It was based on the distinction in the field data of 2005 between core and satellite populations. We defined core populations as those parts that spread around the original centre of the population only by SDD. An "export function" $f_{M}$ was introduced that represented the fraction of seeds that was dispersed out of the core region by MDD. As there was no empirical evidence for any individuals outside the core area until 2001 but as few outposts may have remained undetected, we used a modified step function to describe the onset of seed export some years after the seed sowing:

$$
\begin{aligned}
& f_{M}=0 \text { for } t<3 \text { (years } 1998 \text { and 1999) } \\
& f_{M}=\beta / 2 \text { for } t=3 \text { (seed dispersal in year 2000) } \\
& f_{M}=\beta \text { for } t \geq 4
\end{aligned}
$$

We determined parameter $\beta$ (Table 2 ) by comparison of model development in this scenario with the core population in 2005 (mainly the $\mathrm{n}_{25}$-values). Any other parameters (e.g., the fraction $f_{S}$ of SDD or its average distance $a_{M}$ ) were assumed to remain unchanged in the period from 2001 to 2005.

The "non-random dispersal scenario" (3) explicitly considered the non-random distribution of the seeds exported from the core population (which were treated as "lost" in scenario 2). We took the distribution of ant nests and of habitat properties of the three sites explicitly into account and modelled population development under consideration not only of SDD but also 
of non-random MDD. This scenario we used to create spatial representations of the populations that could be compared with the field mapping in 2005 and to derive parameters that characterised MDD to each nest (dropping rates $p_{d}$, fractions of redistribution around nests $f_{R}$, average redistribution distance around nests $a_{R}$; Table 2 ).

\section{Results}

Field data

While in the period until 2001 all M. pratense populations spread largely isotropically around the area of origin (Heinken, 2004; Winkler and Heinken, 2007), in 2005 species distribution at all sites deviated substantially both from the first pattern and from each other (see Figs. 2-4, upper figures). Population M1 (Fig. 2) again exhibited a diffusion-like spread pattern (a densely populated area with a less dense margin) of approximately $10 \mathrm{~m}$ around the sown plot, but a large section bordering in the $S$ under the canopy of young oak trees was sparsely colonized. Beside the core population a small satellite population had established in the $\mathrm{E}$ around the closest Formica rufa nest mound. The density of the core population of M2 (Fig. 3) was much lower than that at site M1, but several satellite populations existed. Most of them were scattered around the closest red wood ant nest mound in the NW, some single $M$. pratense individuals around a nest in the NE, and a dense satellite population had established between these two nests. In M3 (Fig. 4) the core population covered a smaller area than in $\mathrm{M} 1$ and $\mathrm{M} 2$, but a circular satellite population with a diameter of 35-40 $\mathrm{m}$ and approx. 35,000 individuals had formed in the SW, with a Formica nest mound at its SE margin. Establishment of remote satellite populations had also occurred to ENE and W in the direction to and around other ant nests.
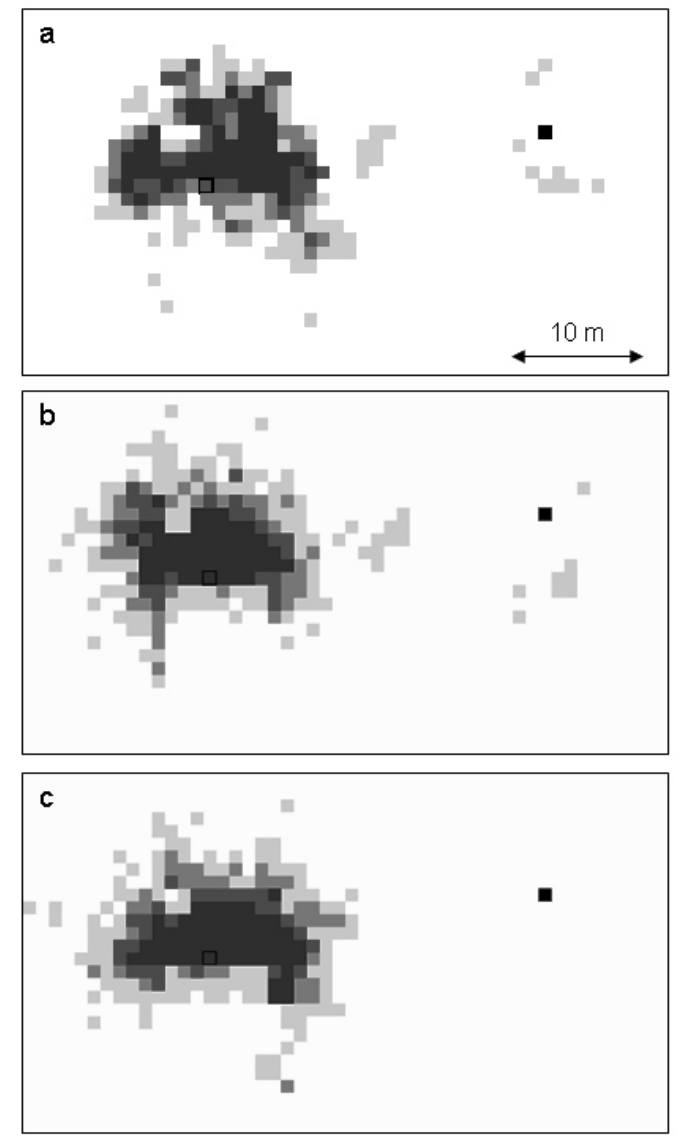

Fig. 2. Population spread of Melampyrum pratense in 2005 after seed sowing in 1997 (site M1): field mapping (a), simulated values obtained with the projection scenario (b: assumption of only SDD; parameters of Table 1), and a non-random MDD-scenario simulation snapshot (c; parameters of Table 2 included). Each square has an area of $1 \mathrm{~m}^{2}$. Grey tones denote different degrees of occupation of $25^{\star} 25 \mathrm{~cm}^{2}$ sub-squares $(1-4,5-8,9-12,13-16)$. The origin of populations $\left(1 \mathrm{~m}^{2}\right)$ is given by a black frame, and the position of ant nests included in seed transport (see Table 2 ) by black squares. 

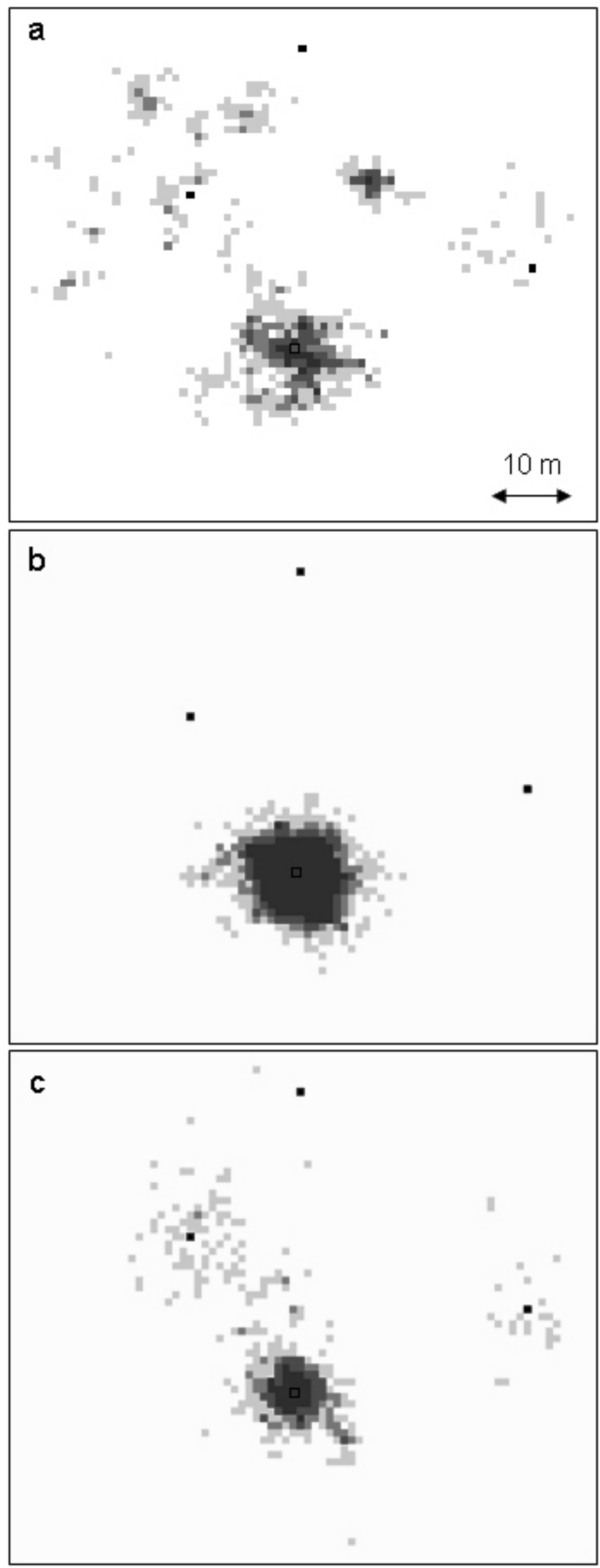

Fig. 3. Population spread of Melampyrum pratense in 2005 after seed sowing in 1997 (site M2). For details see legend to Fig. 2. 

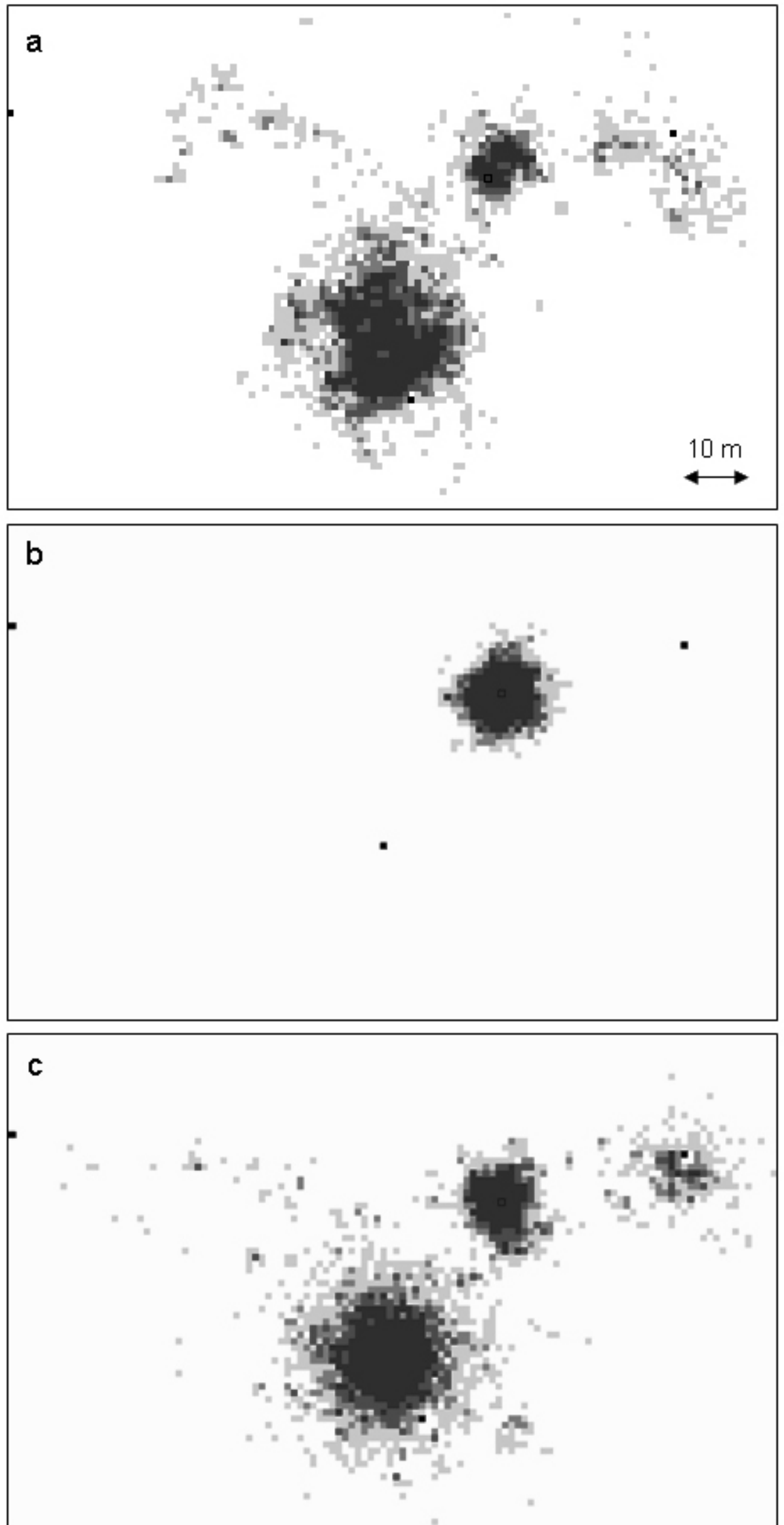

Fig. 4. Population spread of Melampyrum pratense in 2005 after seed sowing in 1997 (site M3). For details see legend to Fig. 2. 
After 8 years the farthest $M$. pratense individuals were $30.2 \mathrm{~m}$ (M1), $48.2 \mathrm{~m}$ (M2) and $51.7 \mathrm{~m} \mathrm{(M3)}$ off the centre of the sown plot. Mean spread rate over all populations increased from $0.91 \mathrm{~m}$ per year in the first phase after seed sowing to $5.12 \mathrm{~m}$ per year in the second phase. While after 4 years there were no differences in spread rates between the three populations, all populations differed markedly in the following 4 years of dispersal (ANOVA with subsequent Tukey post hoc tests, Table 3, Fig. 5). Here, mean spread rate in 16 sectors was lowest in M1, medium in M2 and maximal in M3 $(2.05,5.35$ and $7.95 \mathrm{~m}$ per year). A significant effect of spread phase $\left(F_{1,45}=81.15, p<0.001\right)$ and of the interaction between phase and population in the repeated measures ANOVA $\left(F_{2,45}=15.09, p<0.001\right)$ indicated that spread rates were different between phases and that the effect of phase differed among populations. However, spread rates were significantly higher in the second phase in all three populations (paired $t$-test, d.f. $=15 ; \mathrm{M} 1: \mathrm{t}=2.59, \mathrm{p}=0.021 ; \mathrm{M} 2 \mathrm{t}=4.58, \mathrm{p}<0.001 ; \mathrm{M} 3 \mathrm{t} \mathrm{t}=$ 7.68, $\mathrm{p}<0.001)$.

Table 3. Summary of ANOVA results for the effects of population (M1-M3) on the spread rate of Melampyrum pratense from population establishment after seed sowing in phase 1 ( 3 years of dispersal) and phase 2 (4 years of dispersal)

\begin{tabular}{lcccccccc}
\hline & \multicolumn{4}{c}{ Phase 1 (1998-2001) } & \multicolumn{3}{c}{ Phase 2 (2001-2005) } \\
\hline Source & d.f. & Sum of squares & $F$ & $p$ & $\begin{array}{c}\text { Sum of } \\
\text { Squares }\end{array}$ & $\mathrm{F}$ & $\mathrm{p}$ \\
& & & & & & & \\
\hline Population & 2 & 0.27 & 0.43 & 0.652 & 280.63 & 14.60 & $<0.001$ \\
Error & 45 & 14.07 & & & 433.41 & 9.63 & \\
\hline
\end{tabular}

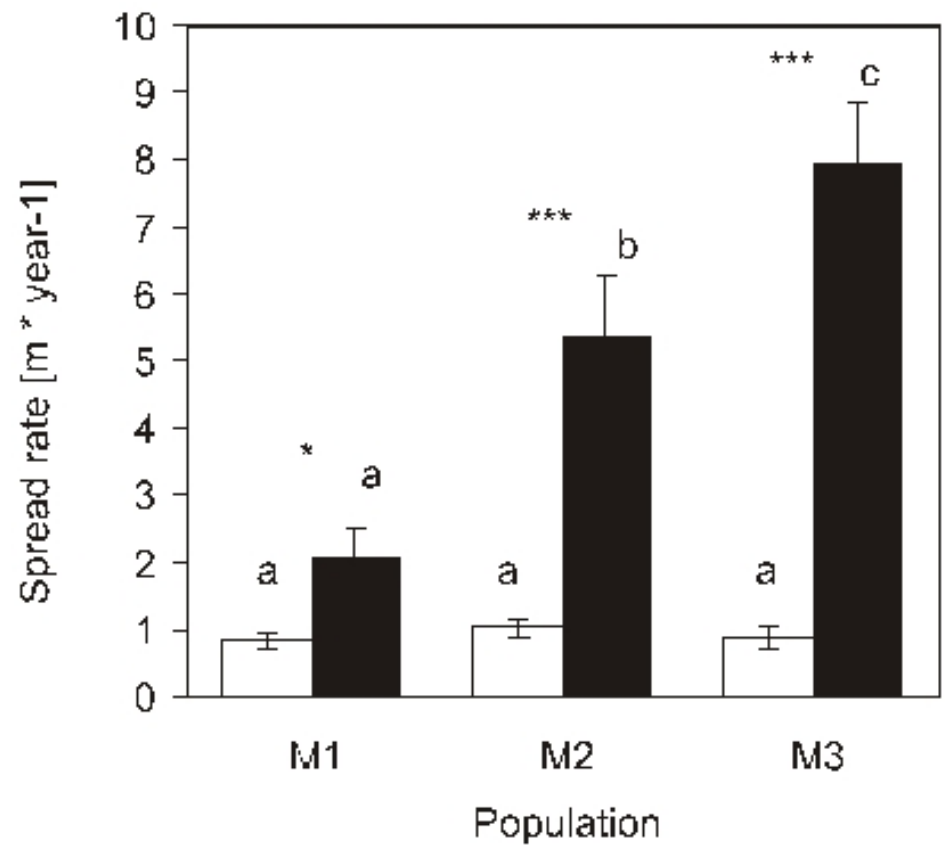

\section{8-2001 2001-2005}

Fig. 5. Mean spread rates of the three Melampyrum pratense populations for the initial and subsequent phase of population spread after seed sowing. Spread rates were calculated by the radial distances between the outermost individuals in 16 directional sectors. Bars with different letters are significantly different ( $p<0.05$, ANOVA and subsequent Tukey-test). Asterisks indicate significance levels $\left(^{*}, p<0.05 ;{ }^{* *},<0.01 ;{ }^{* * *}, p<0.001\right)$ of paired t-tests following repeated measures ANOVA. Error bars denote standard errors. 


\section{Projection of population spread until 2005: short-distance dispersal}

The results of population-spread projection until 2005 under the "projection scenario" are summarised in Fig. 6 (second columns of each group). Projections started from a good correspondence between empirical and simulation results in 2001 as a result of the parameterestimation process described by Winkler and Heinken (2007). In 2005 the projection results (for snapshots see Figs. 2-4, central figures) showed strong deviations from field results with different tendencies (cf. first and second columns of each group in Fig. 6). Judged by the characteristics $X, n_{25}$, and $n_{100}$ the model well predicted empirical findings at site $M 1$. For $M 2$, the number of $25 \times 25 \mathrm{~cm}^{2}$ cells including at least one individual $\left(\mathrm{n}_{25}\right)$ and especially population sizes $X$ were overestimated by the model, whereas $n_{100}$ was slightly underestimated: In the model more individuals were spread over a smaller area than in the field. This lower spread in the model projection is still clearer at site M3 where $n_{25}, n_{100}$, and $r_{\max }$ were all clearly higher in the field. Maximum spread distances were consistently underestimated by the model in the projection scenario which gave as an average over 50 simulation runs only $71 \%$ (M1), $24 \%$ (M2) or $26 \%$ (M3) of the field values.
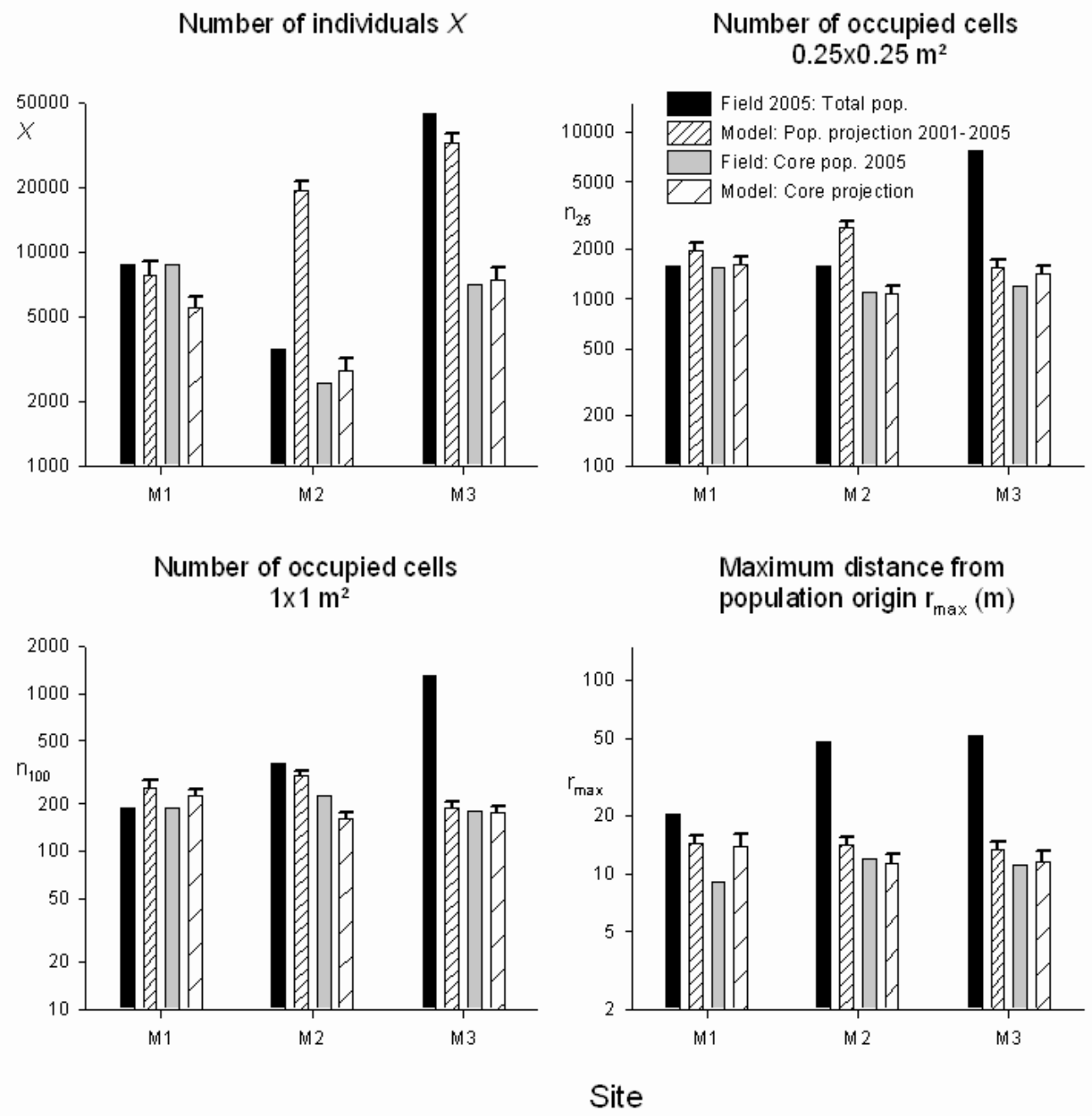

Fig. 6. Field results and projected model outputs for 2005. Empirical values for total and core populations were estimated from the plant distributions (Figs. 2-4). Model projection values were obtained under the assumption of only SDD (parameters of Table 1) estimated from the 1998-2001 period. Simulated core populations likewise assumed only SDD, but also loss by seed export (eq. 2). For model output mean values and standard deviations are given (50 simulation runs).

\section{Core population: short-distance dispersal and seed export}

The "core-development scenario" gave the parameter $\beta$ of the export function eq. 3. For M1 only a small fraction of seeds were lost for the core population due to MDD $(\beta=0.1)$, whereas it was much higher at the other sites ( $\beta=0.5$ or 0.55 , resp.). Judged from the $n_{25}$ 
and $\mathrm{n}_{100}$ values the agreement between simulated core-population development (with parameter $\beta$ ) and the respective field data was satisfactory (Fig. 6, third vs. last columns of each group). Remaining differences (especially for $\mathrm{n}_{100}$ at site M2) may indicate some changes in the SDD parameters in the period $2001 \ldots 2005$. The maximum distances $r_{\max }$ predicted by the core-development scenario well met the field data for core populations at sites M2 and M3. At site M1 the model calculations overestimated core spread, but here a comparison is hampered by the unsuitable habitat just within the region of the core population (see above).

\section{Total population: Non-random medium-distance dispersal}

Given the export-function parameters $\beta$ from the core-population scenario the simulations with the "non-random dispersal scenario" made use of the full set of dispersal mechanisms (Fig. 1). Details were expressed by the parameters of Table 2 that gives three adjusted parameter values $\left(p_{d}, f_{R}, a_{R}\right)$ for the different sites and ant nests. Simulations of development of total populations with both SDD and MDD gave results that were in most cases in good agreement with the field data for total populations in 2005 (Fig. 7). This mainly holds for the $n_{25}$-values, which can be determined in the field with higher precision than the X-values, but also for the maximum distance $r_{\max }$. Only the full MDD model version allowed reproducing the empirically given maximum distances, as visualised by field maps and typical simulation snapshots shown in Figs. 2-4 (lower figures). Simulations with the "non-random dispersal scenario" (results not shown) also corroborated the existence of a lag in seed export (eq. 3): MDD of seeds from the beginning (year 1998) would lead to outposts of the species already in the initial phase until 2001 , in contrast to the field results.
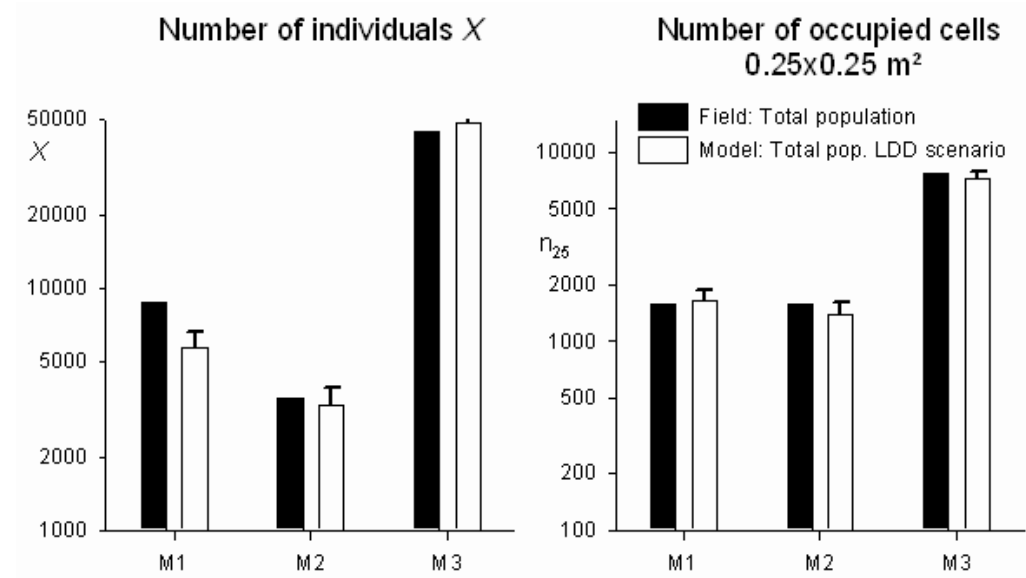

Number of occupied cells $1 \times 1 \mathrm{~m}^{2}$

Maximum distance from population origin $r_{\max }(m)$
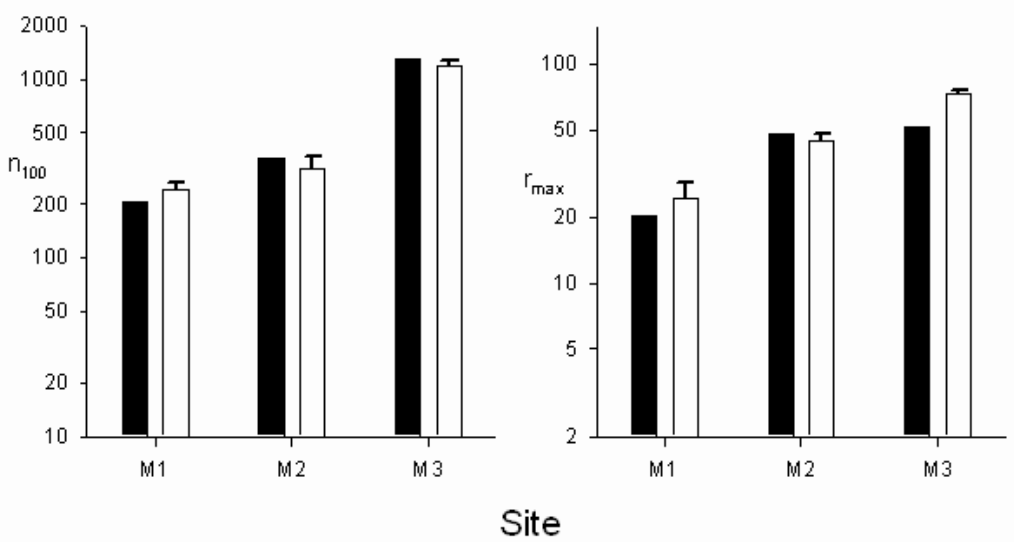

Fig. 7. Field results and model output for the total population in 2005. Simulation of total populations assumed SDD (Table 1) and non-random MDD plus deposition of seeds exported from the regions of origin (nest positions and parameters in Table 2). 


\section{Discussion \\ Mechanisms and consequences of non-random dispersal towards red wood ant nests}

Our study demonstrated that a spatially explicit model that explained population growth and spread of Melampyrum pratense in an initial phase after artificial introduction (Winkler and Heinken, 2007) by only random dispersal was not able to predict population patterns in a subsequent phase: species spread in the field was much higher and more irregular than expected. Only an extended, stratified model introducing non-random, medium-distancedispersal towards nest mounds of red wood ants by a set of general transport and deposition rules, together with additional ad-hoc assumptions, reproduced the complex field patterns 8 years after seed sowing. This modelling success made us confident that Formica rufa ants now, after a delay of several years, transported seeds of $M$. pratense to their nests and redispersed a fraction of them in all populations.

Colonies of the $F$. rufa species group occupy large territories and collectively use distinct foraging routes radiating out in different directions from a nest mound (Rosengren and Fortelius, 1986). Territory sizes vary between 200 and 2,500 $\mathrm{m}^{2}$, with distances from the nest to the territory border usually between 20 and $30 \mathrm{~m}$ (Mabelis, 1979a; Skinner, 1980a). Red wood ants, which mainly feed on honey dew secretions of aphids on trees and animal prey (Skinner, 1980b), are known to disperse M. pratense seeds, their elaiosomes being an additional lipid source. Remarkably long seed dispersal distances of tens of metres are documented due to their large territories (Sernander, 1906).

Our results clearly corroborate and quantify dispersal processes by ants suggested from direct observations to be responsible for the increase in population cover of $M$. pratense: Ants pick up seeds and carry them into their nests, in doing so seeds are dropped on the way (e.g. Gorb and Gorb, 2003). In the nest the elaiosomes are eaten or fed to larvae (Fischer et al., 2005), and varying proportion of seed is then discarded around the nest or at territory borders (Ohkawara et al., 1996; Gorb and Gorb, 2003).

According to Gorb and Gorb (1999) dropping rates of relocated diaspores during transport by red wood ants can be $2-3 \% \mathrm{~m}^{-1}$ for large-seeded myrmecochores like $M$. pratense. Parameters derived in our model are magnitudes lower, and we see no reason why large amounts of seeds with elaiosomes should remain on the frequented ant trails. Indeed, in other systems with other ant species, no significant seed drops were observed and most seeds were transported to the nests (Higashi et al., 1989).

In our model $M$. pratense benefitted from seeds being redistributed around nests. We mainly obtained redistribution fractions of only a few percent up to $40 \%$. In a study by Kjellsson (1985), 16-20\% of Carex pilulifera seeds were relocated out of the ant nests of Myrmica ruginodis, and Higashi et al. (1989) found that seeds of Trillium sp. were mostly located outside ant nests ( $M$. ruginodis and other smaller species). These findings are in contrast to the extremely low fractions of seeds found to be re-dispersed around the nest at site M1 or nest 3 at site M2. Most likely these colonies were involved in dispersal later than 2001, as was generally assumed in the model. Simulations showed that such a later onset of MDD at site M1 was in good agreement with the field pattern (results not shown).

We could only explain the extremely large satellite population of site M3 assuming that an ant nest had shifted from the centre of this satellite population to its margin towards the end of the investigation period (see Table 2). In fact, colonies of red wood ants are known to move regularly on a decadal timescale (Klimetzek, 1981). However, we did not observe decaying remnants of a mound at this particular place in 2005. Hence we cannot exclude other dispersal vectors, and such vectors must also be evoked in the case of the largest and probably oldest satellite population in the NNE of site M2 which was not explained by our model (see Fig. 3). Small scatterhoarding rodents may also have dispersed $M$. pratense seeds. They exhibit high population densities in forests and their home ranges are similar to those of red wood ants (see Kikkawa, 1964). Rodents may carry seeds up to tens of metres, and some of the gathered seeds may be overlooked, and germinate (e.g. Roth and vander Wall, 2005).

Outposts of M. pratense individuals in 2005 give hints that finally not only the red wood ant colonies directly adjacent to the experimental populations were involved in seed dispersal, but also farther ones. This holds true for nest 3 in site M2 and nests S and W of nest 1 in 
site M3. Seed migration across different Formica rufa colonies may not be retarded, because borderlines between adjacent territories where seeds have been dumped may shift within or between years (Mabelis, 1979b), and food items from one place may thus be carried to two nests even within 1 year.

To our knowledge we first analysed consequences of seed dispersal by ants for spreading plant populations over several years. With a mean of $5.1 \mathrm{~m}$ per year, spread rates of $M$. pratense were much higher than those of other myrmecochorous forest herbs obtained from the study of recent stands adjacent to ancient forests. Here mean migration rates over some decades varied between 0 and $2.3 \mathrm{~m}$ per year for 29 ant-dispersed species (Matlack, 1994; Brunet and von Oheimb, 1998; Dzwonko, 2001). However, in these studies colonization patterns were not solely affected by dispersal processes, because the recruitment of species in the recent forests is often limited by differing soil properties and canopy cover (Flinn and Vellend, 2005). Contrary to M. pratense, most forest herbs are perennial species with low seed production which need several years until the first seed set. Finally, red wood ants as keystone species for MDD were probably not present at the investigated deciduous forest sites, as they are mainly restricted to coniferous and mixed forests (Risch et al., 2005).

In our model we expressed the overall effectiveness of MDD (dispersal by red wood ants) by parameter $\beta$ (eq. 3), and the competition between ant colonies for seeds was given by the rule that the probability of a seed to be transported to a nest is decreasing with its distance from the nest. In fact the density of foraging red wood ants decreases with distance from the nest (Mabelis, 1979b; Lenoir, 2002). Other ant species involved in dispersal were included by the sequence of dispersal rules of Fig. 1. Species of the Formica rufa group are top competitors, while the ant species responsible for SDD are submissive species, coexisting within the F. rufa territories (Savolainen and Vepseläinen, 1989) with colony numbers strongly decreasing towards the nest mound.

\section{Lag-phase in population development}

In our experiment M. pratense populations exhibited a "lag-phase" of spread of some years, followed by a subsequent strong increase in area covered by the population. Obviously red wood ants started MDD activities only after some years. Four explanations are possible: In the initial period (1) M. pratense populations were not within territories of red wood ants, (2) red wood ants did not detect the seeds although they were distributed within their territories, (3) seeds were not yet attractive as food resources due to their initially small number, or (4) red wood ants did not carry them to their nest, but removed the elaiosomes in situ.

(1) Red wood ants collect food items within their whole territory. Our initial M. pratense populations were between 25-30 metres apart from the closest red wood ant nests (Table 2), i.e. in the border area of territories. Until 2001 foraging ant workers were observed within the population areas of M2 and M3, but not within M1 (Heinken, 2004). Thus we must assume that only population M1, with the lowest MDD until 2005, not encroached into a red wood ant territory before 2001.

(2) It is unlikely that worker ants did not find seeds of the populations M2 and M3 within the first 3 years: Even prey placed far from an ant trail was usually found within $30 \mathrm{~min}$. in a study of Lenoir (2002). At the beginning of our experiment, ants may not have been used to handling M. pratense seeds, and may thus not have taken them. However, smaller species like Formica fusca and Myrmica ruginodis immediately transported seeds here, and our own, unpublished experiments in 2006 indicated a rapid detection and transport of previously unknown seed species from depots by F. rufa (see also Peters et al., 2003).

(3) To forage, Formica rufa worker ants leave the nest on constant trunk trails, spread over the territory and repeatedly come back to previously haunted areas with "Ortstreue" (site allegiance) (Rosengren and Fortelius, 1986). Retrieval of previously unknown food items far off trunk trails, like $M$. pratense seeds, is performed by "scouts", worker ants specialized in searching randomly (Horstmann, 1973; Lenoir, 2002). These may quickly recruit other worker ants to carry away the food, especially if the food patches are rich (Horstmann et al., 1982; Lenoir, 2002). Possibly seed numbers were too low in the first phase of population spread to induce recruitment of workers carrying away any seed to the nest. $M$. pratense elaiosomes 
were surely a food resource of only minor importance, because at most $60 \mathrm{~g}$ seeds were produced per season and population until 2000 , while a red wood ant colony needs several kg prey per season (see Skinner, 1980b). In the second phase of spread M. pratense elaiosomes became most likely a much more important food source as seed number increased rapidly.

(4) At site M3 already in 2000 dispersal was preferentially in the direction of nest 2 (Winkler and Heinken, 2007), and in M2 the farthest outpost of $M$. pratense in 2001 already appeared in the direction of nest 1 (cf. Heinken, 2004; Fig. 2). Here seeds must have been detected but were either dropped after short distances, or not yet transported at all. Actually red wood ants may nibble off elaiosomes without transporting the seeds (Gorb and Gorb, 2003; see also Ohkawara et al., 1996 for other ant species), or the elaiosome is chewed and sucked on the way to the nest (Seifert, 1996). Our results suggest that this may occur especially among non-profitable food patches and far off the nest mound.

In conclusion, different and interacting causes for the observed time lag are possible, but a change of seed removal and transport behaviour of the ants with the growth of a new food resource seems to be the most probable explanation at least in the case of populations M2 and $\mathrm{M} 3$.

As observed here on a local scale for the native $M$. pratense, many invasive plant species display a long period of slow initial spread following introduction before they spread rapidly (Hobbs and Humphries, 1995; Pyšek and Hulme, 2005). Several possible mechanisms for such a lag-phase-behaviour have been put forth, e.g. selection and adaptation to the local environment including development of genotypes with increased dispersal ability, and the induced improvement of extrinsic factors such as soil disturbance, nutrient enrichment, climate and dispersal vectors (see Pyšek and Hulme, 2005 for a comprehensive review of hypotheses). In an empirical study of Frappier et al. (2003) the rate of local invasion of the endozoochorous shrub Rhamnus frangula appeared to have been significantly slower in the initial stages of expansion, possibly due to early local selection and adaptation to the peculiar environmental conditions of the study site. We were able to follow a lag-phase in detail by observation and thus to search for mechanisms by modelling. Complex models help to detect relevant aspects of disperser behaviour and its consequence on the spreading population (Westcott et al., 2005; Buckley et al., 2006; Morales and Carlo, 2006). For the M. pratenseant system we demonstrated that an induced change of behaviour of a potential disperser (here: red wood ants) that enhances dispersal distances could account for a lag-phase. This emergence of an ant-plant interaction turns out to be an example for an induced improvement of an extrinsic factor according to Pyšek and Hulme (2005), and the M. pratense-ant system is likely to be a meaningful example for a lag-phase in species spread already operating in case of a native species. As our study showed both the plant species and the ants will benefit from their interaction: Each component in the dispersal hierarchy enhances population growth and spread (see also Winkler and Heinken, 2007), and seeds of $M$. pratense form a food source of increasing importance for the ants.

\section{Implications for the prediction of plant species spread}

The complete study from 1997 until 2005 showed a transition from an experiment under controlled conditions to field observations that include an increasing amount of irregular features. This formation of increasingly complex patterns demanded the introduction of important features such as a lag phase in the onset of dispersal and non-random medium-distance dispersal for its explanation. Other temporal and spatial variations of plant-animal interactions may furthermore alter dispersal patterns substantially (for myrmecochory see Gove et al., 2007; Manzaneda et al., 2007). In our study spread patterns of M. pratense depended on nest mound distribution of the red wood ant as keystone disperser which will change with time and which is different between localities. Additional dispersal interactions with other animal vectors, e.g. endozoochory by large mammalian herbivores, may occur. Also habitat properties affecting seedling emergence or seed production will change in an unpredictable manner over different spatial scales. In a larger spatial context, migration rates will additionally be strongly altered by habitat fragmentation (Higgins et al., 2003). Thus we must conclude that - even on a local scale like one forest patch - any extrapolations of population 
spread rates and patterns of animal-dispersed plants from short-term observations should be handled with caution. In a broader context our study gives an example for the fundamental problems linked with long-term prediction of species distributions and abundances (Benincà et al., 2008; Thuiller et al., 2008).

Currently seed dispersal by wind is probably the only dispersal syndrome where mechanistic models can be applied with any confidence (Schurr et al., 2005). Thus there is a need for a better knowledge of the patterns of interaction between plants, animal dispersal vectors and other factors affecting species spread (Buckley et al., 2006). Only then reliable predictions on species spread over large areas and longer time periods will be possible, which are needed to evaluate the ability of species to cope with future environmental and landscape changes. Our system may be representative of establishing and spreading plant populations after having crossed habitat edges by long-distance dispersal events. According to Cain et al. (1998), Powell \& Zimmermann (2004) and Nathan (2006) this combination of longdistance dispersal with intense spread on a local scale is the only way by which plant species can expand or shift their ranges, and thus may ensure their survival in the current context of climate changes and habitat fragmentation.

Acknowledgements - We thank Dorit Siebert for assistance during the field work in 2005 and Ute Becker for statistical advice. We are also are indebted to Daniel Prati, two anonymous reviewers and Johannes Kollmann for their valuable comments on earlier versions of the manuscript.

\section{References}

Beattie, A.J., Hughes, L., 2002. Ant-plant interactions. In: Herrera, C. M., Pellmyr, O. (Eds.), Plantanimal interactions. An evolutionary approach. Blackwell, pp. 211-235.

Benincà, E., Huisman, J., Heerkloss, R., Jöhnk, K.D., Branco P., van Nes, E.H., Scheffer, M., Ellner, S.P., 2008. Chaos in a long-term experiment with a plankton community. Nature 451, 822-825.

Brunet, J., von Oheimb, G., 1998. Migration of vascular plants to secondary woodlands in southern Sweden. J. Ecol. 86, 429-438.

Buckley Y.M., Anderson, S., Catterall, C.P., Corlett, R.P., Engel, T., Gosper, C.R., Nathan, R., Richardson, D.M., Setter, M., Spiegel, O., Vivian-Smith, G., Voigt, F.A., Weir, J.E.S., Westcott, D.A., 2006. Management of plant invasions mediated by frugivore interactions. J. Appl. Ecol. 43, 848-857.

Cain, M., Damman H. and Muir, A., 1998. Seed dispersal and the Holocene migration of woodland herbs. Ecol. Monographs, 68, 325-347.

Dzwonko, Z., 2001. Migration of vascular plant species to a recent wood adjoining ancient woodland. Acta Soc. Botan. Polon. 70, 71-77.

Ehrlén, J., Eriksson, O., 2000. Dispersal limitation and patch occupancy in forest herbs. Ecology 81, 1667-1674.

Fischer, R.C., Ölzant, S.M., Wanek, W., Mayer, V., 2005. The fate of Corydalis cava elaiosomes with an ant colony of Myrmica rubra: elaiosomes are preferentially fed to larvae. Insectes Sociaux 52, $55-62$.

Flinn, K.M., Vellend, M., 2005. Recovery of forest plant communities in post-agricultural landscapes. Frontiers Ecol. Environ. 3, 243-250.

Frappier, B., Lee, T.D., Olson, K.F., Eckert, R.T., 2003. Small-scale invasion pattern, spread rate, and lag-phase behaviour of Rhamnus frangula L. Forest Ecol. Manage. 186, 1-6.

Gibson, W., 1993. Selective advantages to hemiparasitic annuals, genus Melampyrum, of a seeddispersal mutualism involving ants I: Favourable nest sites. Oikos 67, 334-344.

Gomez, C., Espadaler, X., 1998. Myrmecochorous dispersal distances: a world survey. J. Biogeogr. $25,573-580$

Gorb, E., Gorb, S., 2003. Seed dispersal by ants in a deciduous forest ecosystem: mechanisms, strategies, adaptations. Kluwer Academic Publishers.

Gorb, S.N., Gorb, E.V. 1999. Dropping rates of elaiosome-bearing seeds during transport by ants (Formica polyctena Foerst.): Implications for distance dispersal. Acta Oecol. 20, 509-518.

Gove, A.D., Majer, J.D., Dunn, R.R., 2007. A keystone ant species promotes seed dispersal in a "diffuse" mutualism. Oecologia 153, 687-697.

Heinken, T., 1995. Naturnahe Laub- und Nadelwälder grundwasserferner Standorte im niedersächsischen Tiefland: Gliederung, Standortsbedingungen, Dynamik. Diss. Bot. 239, 1-311. 
Heinken, T., 2004. Migration of an annual myrmecochore: a four-year-experiment with Melampyrum pratense L. Plant Ecology 170, 55-72.

Higashi, S., Tsuyuzaki, S., Ohara, M., Ito, F., 1989. Adaptive advantages of ant-dispersed seeds in the myrmecochorous plant Trillium tschoskii (Liliaceae). Oikos 54, 389-394.

Higgins, S.I., Lavorel, S., Revilla, E., 2003. Estimating plant migration rates under habitat loss and fragmentation. Oikos 101, 354-366.

Hobbs, R.J., Humphries, S.E., 1995. An integrated approach to the ecology and management of plant invasions. Conserv. Biol. 9, 761-770.

Horstmann, K., 1973. Untersuchungen zur Arbeitsteilung unter den Außendienstmitarbeiterinnen der Waldameise Formica polyctena Foerster. Z. Tierpsychol. 32, 532-543.

Horstmann, K. Bitter, A., Ulsamer, P., 1982. Nahrungsalarm bei Waldameisen (Formica polyctena Foerster). Insectes Sociaux 29, 44-66.

Kikkawa, J., 1964. Movement, activity and distribution of the small rodents Clethrionomys glareolus and Apodemus sylvaticus in woodland. J. Anim. Ecol. 33, 259-299.

Kjellsson, G., 1985. Seed fate in a population of Carex pilulifera L. I. Seed dispersal and ant-seed mutualism. Oecologia 85, 416-423.

Klimetzek, D., 1981. Population studies on hill building wood-ants of the Formica rufa-group. Oecologia $48,418-421$.

Laakso, J., Setälä, H., 1998. Composition and trophic structure of detrital food web in ant nest mounds of Formica aquilonia and in the surrounding forest soil. Oikos 81, 266-278.

Lenoir, L., 2002. Can wood ants distinguish between good and bad food patches on the forest floor? Europ. J. Soil Biol. 38, 97-102.

Mabelis, A.A., 1979a. Nest splitting by the red wood ant (Formica polyctena Foerster). Netherlands J. Zool. 29, 109-125.

Mabelis, A.A., 1979b. Distribution of red wood ants (Formica polyctena Först.) over the foraging area of their nest, and the influence of a conspecific neighbouring population. Netherlands J. Zool 29, 221-232.

Manzaneda, A.J., Rey, P.J., Boulay, R., 2007. Geographic and temporal variation in the ant-seed dispersal assemblage of the perennial herb Helleborus foetidus L. (Ranunculaceae). Biol. J. Linn. Soc. 92, 135-150.

Masselink, A.K., 1980. Germination and seed population dynamics in Melampyrum pratense L. Acta Bot. Neerl. 29, 451-468.

Matlack, G.R., 1994. Plant species migration in a mixed-history forest landscape in eastern North America. Ecology 75, 1491-1502.

Midgley, G.F., Hughes, G.O., Thuiller, W., Rebelo, A.G., 2006. Migration rate limitations on climate change-induced range shifts in Cape Proteaceae. Divers. Distrib. 12, 555-562.

Morales, J.M., Carlo, T.A., 2006. The effect of plant distribution and frugivore density on the scale and shape of dispersal kernels. Ecology 87. 1489-1496.

Nathan, R., 2006. Long-distance dispersal of plants. Science 313, 786-788.

Neilson, R.P., Pitelka, L.F., Solomon, A.M., Nathan, R., Midgley, G.F., Fragoso, J.M.V., Lischke, H., Thompson, K., 2005. Forecasting regional to global plant migration in response to climate change. Bioscience 55, 749-759.

Neubert, M.G., Caswell, H., 2000. Demography and dispersal: Calculation and sensitivity analysis of invasion speed for structured populations. Ecology 81, 1613-1628.

Ohkawara, K., Higashi, S., Ohara, M., 1996. Effects of ants, ground beetles and the seed-fall patterns on myrmecochory of Erythronium japonicum Deene (Liliaceae). Oecologia 106, 500-506.

Olmstead, R.G., DePamphilis, C.W., Wolfe, A.D., Young, N.D., Elisens, W.J., Reeves, P.J., 2001. Disintegration of the Scrophulariaceae. Am. J. Bot. 88, 348-361.

Peters, M., Oberrath, R., Böhning-Gaese, K., 2003. Seed dispersal by ants: are seed preferences influenced by foraging strategies or historical constraints? Flora 198, 413-420.

Petersen, P.M., Philipp, M., 2001. Implantation of forest plants in a wood on former arable land: a ten year experiment. Flora 196, 286-291.

Powell, J.A., Zimmermann, N.E., 2004. Multiscale analysis of active seed dispersal contributes to resolving Reid's paradox. Ecology 85, 490-506.

Primack, R.B., Miao, S.L., 1992. Dispersal can limit local plant distribution. Conserv. Biol. 6, 513-519.

Pyšek, P., Hulme, P., 2005. Spatio-temporal dynamics of plant invasions: Linking pattern to process. Écoscience 12, 302-315.

Risch, A.C., Jurgensen, M.F., Schütz, M., Page-Dumroese, D.S., 2005. The contribution of red wood ants to soil $\mathrm{C}$ and $\mathrm{N}$ pools and $\mathrm{CO}_{2}$ emissions in subalpine forests. Ecology 86, 419-430.

Rosengren, R., Fortelius, W., 1986. Ortstreue in foraging ants of the Formica-rufa group - hierarchy of orienting cues and long-term memory. Insectes Sociaux 33, 306-337. 
Roth, J.K., Vander Wall, S.B., 2005. Primary and secondary seed dispersal of bush chinquapin (Fagaceae) by scatterhoarding rodents. Ecology 86, 2428-2439.

Savolainen, R., Vepsäläinen, K., 1989. Niche differentiation of ant species within territories of the wood ant Formica polyctena. Oikos 56, 3-16.

Schurr, F.M., Bond, W.J., Midgley, G.F., Higgins, S.I., 2005. A mechanistic model for secondary seed dispersal by wind and its experimental validation. J. Ecol. 93, 1017-1028.

Seifert, B., 1996. Ameisen: beobachten, bestimmen. Naturbuch-Verlag, Augsburg.

Sernander, R., 1906. Entwurf einer Monographie der europäischen Myrmekochoren. Kunglika Svenska Vetenskapsakademie Handlingar 4, 1-410.

Skinner, G. J., 1980a. Territory, trail structure and activity patterns in the wood-ant, Formica rufa (Hymenoptera: Formicidae) in limestone woodland in North-West England. J. Anim. Ecol. 49, 381394.

Skinner, G.J., 1980b. The feeding habits of the wood-ant, Formica rufa (Hymenoptera: Formicidae) in limestone woodland in north-west England. J. Anim. Ecol. 49, 417-433.

Thuiller, W., Albert, C., Araújo, M.B., Berry, P.M., Cabeza, M., Guisan, A., Hickler, T., Midgley, G.F., Paterson, J., Schurr, F.M., Sykes, M.T., Zimmermann, N.E. (2008): Predicting global change impacts on plant species' distributions: Future challenges. Perspect. Plant Ecol. Evol. Systematics 9, 137-152.

Thompson, K., Bakker, J.P., Bekker, R.M., 1997. The soil seed banks of North West Europe: Methodology, density and longevity. Cambridge Universtiy Press, Cambridge.

Van der Veken, S., Rogister, J., Verheyen, K., Hermy, M., Nathan, R. 2007. Over the (range) edge: a 45-year transplant experiment with the perennial forest herb Hyacinthoides non-scripta. J. Ecol. 95, 343-351.

Volin, J.C., Lott, M.S., Muss, J.D., Owen, D., 2004. Predicting rapid invasion of the Florida Everglades by the Old World Climbing Fern (Lygodium microphyllum). Divers. Distrib. 10, 439-446.

Westcott, D.A., Bentrupperbauer, J., Bradford, M.G., McKeown, A., 2005. Incorporating disperser movement and behaviour patterns into models of seed dispersal. Oecologia 146, 57-67.

Whigham, D.F., 2004. Ecology of woodland herbs in temperate deciduous forests. Annu. Rev. Ecol. Evol. Syst. 35, 583-621.

Winkler, E., Heinken, T., 2007. Spread of an ant-dispersed annual herb: an individual-based simulation study on population development of Melampyrum pratense L. Ecol. Model. 203, 424-438. 